\title{
Injuries of the spine sustained during gymnastic activities
}

\author{
J R SILVER， D D SILVER， J J GODFREY
}

\begin{abstract}
Between 1954 and 1984, 38 patients were seen as a result of gymnastic activities. Thirty three were men, five were women, and their ages ranged from 12 to 54 , the mean age being 20 . Thirty one had spinal injuries (28 in the cervical region, three in the thoracolumbar region), two no definite injury, and for five the information was incomplete. The accidents occurred largely because gymnasts landed on their heads, the force being transmitted to the cervical spine. Most took place in gymnasiums and were caused by a failure of supervision.
\end{abstract}

\section{Introduction}

Spinal injuries occur during gymnastic activities for two reasons. Firstly, the participants lead with their heads forward during somersaults, and, secondly, great force can be achieved by using equipment such as trampettes or exercises done from a height. When injuries of all types are considered together gymnastics has a good record. Sparks compared the incidence of injury during physical education with the incidence during other sporting activities at Rugby School over the past 30 years. ${ }^{1} \mathrm{He}$ found the incidence of injury during gymnastics (18 cases per 10000 hours) to be far less than that during rugby football (198 cases per 10000 hours) and to be comparable with that during fives.

Serious injuries of the cervical spine do, however, occur and may cause severe paralysis. Young et al found 18 out of 6014 patients admitted with spinal injury in 1982 to have been injured during

\footnotetext{
National Spinal Injuries Centre, Stoke Mandeville Hospital, Aylesbury HP21 8AL

J R SILVER, FRCP, FRCPED, consultant in spinal injuries D D SILVER, student

Childwell, Liverpool L16 7QT

J J GODFREY, MB, BS, general practitioner

Correspondence to: Dr Silver.
}

gymnastic activity. ${ }^{2}$ Frankel $e t$ al found five cases out of a total of 682 patients, all cervical injuries. ${ }^{3}$ Shields et al reported five gymnastics injuries out of 1600 admissions, ${ }^{4}$ and Steinbruck and Paeslack, out of a total of 2587 patients recorded 12 gymnastic accidents causing tetraplegia and six causing paraplegia. ${ }^{5}$

Between 1954 and 1984 we saw 38 patients who had been injured in gymnastic accidents, 31 of whom had spinal injuries. There were four main sources of injury: the sport of gymnastics, gymnastic exercises carried out during physical education at school, gymnastics carried out in the forces or police, and recreational activities or fooling about. We began this study in 1973, and a prospective questionnaire was developed with the help of two international gymnasts who had been injured in gymnastic accidents. Once the questionnaire was agreed on it was given to patients at the time of admission; it was sent out to other patients identified as gymnasts from their notes. Here we discuss the causes of spinal injury and ways of preventing it.

\section{Patients and their injuries}

Between 1954 and 1984 we studied 38 patients. Most were treated by one of the authors at the Liverpool Regional Paraplegic Centre between 1965 and 1970, and at the National Spinal Injuries Centre between 1970 and 1985 , although a few case histories were sent from the Midlands Spinal Injuries Centre. There were 33 men and five women. Their ages ranged from 12 to 54 with a mean age of 20 and a median age of 19 . Seventeen of the gymnasts were club standard, four were county standard, three were national standard, and one was professional. Nine were beginners, two were schoolboys, and the standard of the remaining two was unknown.

Of the 38,31 had suffered cord injuries leading to complete paralysis in 24 cases, incomplete paralysis in seven, and no deficit in two (the information was incomplete for the five remaining patients). The cord injuries were predominantly at the level of the 4th to the 7 th cervical segment (table I), which correlates with the findings in studies of injuries sustained while playing rugby and during trampolining ${ }^{78}$ and in large series of spinal injuries sustained in road traffic accidents. Of the three patients with thoracolumbar injuries, two were injured when vaulting and one in a fall.

Most of the injuries affected the lower cervical vertebrae. Thirty of the patients had flexion injuries, three patients had extension injuries, and in five cases the mechanism of injury was unknown. 


\section{How injuries were sustained}

Thirty three of the patients were injured in a gymnasium and five were doing exercises on their own. Eighteen patients were injured while performing somersaults, 15 in a gymnasium and three socially, 17 doing forward somersaults and one doing a backward one, and 12 using a trampette and three a springboard to gain height and momentum. The three injured during leisure activities were not using equipment.

Of those injured while using equipment, 15 were using a trampette, seven were using a springboard, two were using horizontal bars, one fell from a rope ladder, one fell from parallel bars, and three were exercising on the floor.

We found many examples of injuries occurring when supervision was inadequate. In three cases the coach was not capable of checking the exercise; in one case the coach could not do the exercise and called a studen to demonstrate it, and in two cases the coach was injured while demonstrating how the exercise should be done. In one case the coach was present and qualified and the setting was correct with appropriate catchers, but the gymnast, of international standard, was showing off to the class and failed to complete the exercise, injuring herself as a result.

Case 1-The patient, aged 30 under detention, was ordered to do a forward somersault over a rope. There were no mats or catchers and he landed on his head, breaking his neck.

Case 2-The patient, who was club standard, vaulted too far over a horse, landing on his head. He was tired after an evening of weightlifting and wrestling. It was a poorly regulated gymnasium, and the coach was not there to catch.

Case 3-A county standard gymnast attempted a double somersault but was too ambitious; he bounced too hard on the trampette, over-rotated, and landed on his head.

Case 4-A 17 year old schoolboy who was unfamiliar with the club equipment used a springboard to dive over a box; he landed on his head.

Case 5-A serviceman fell while attempting to complete an assault course because he went the wrong way round a rope tied to a tree. He did so because he had missed the previous day's instruction through illness.

Case 6-A rope ladder was not pulled away from a gymnasium wall during a cadet course so that one gymnast could not get her feet in and fell.

Case 7-An exercise was done at a time of the day when the sun shone directly through an open window into the eyes of the performer during a difficult somersault.

Case 8-The patient, a junior soldier, had given up gymnastics because he was frightened of it but was ordered to do a forward somersault off a trampette on to crash mats. There were no catchers, and he had not done this exercise for four months and had "always been scared." He did one forward somersault but was told it was terrible and was ordered to do it again.

In 12 cases there was a failure of general supervision in that boys were fooling about in a gymnasium with the knowledge of the authorities.

\section{Discussion}

Accidents occur during gymnastic activities. In the National Electronic Injury Surveillance System (NEISS) survey from selected casualty departments in 1978, 1540 cases were reported. ${ }^{9}$ Lowry and Leveau found that most injuries were contusions, strains, and sprains with only $4.7 \%$ being fractures. ${ }^{10}$ Garrick and Requa found a high incidence of sprains and strains. ${ }^{11}$

Fractures affecting the spine and spinal cord are fortunately rare. When they do occur they almost invariably affect the cervical spine. Shields et al reported five cases out of 152 sporting accidents as a result of gymnastics. ${ }^{4}$ Young et al reported 18 cases out of a total of 6014. ${ }^{2}$ Steinbruck and Paeslack reported 18 gymnastic injuries among a total of 2587 people with traumatic injuries to their spinal cords. ${ }^{5}$ Our incidence is similar, there being 35 out of about 6000 traumatic admissions. Interestingly, they had 12 tetraplegics compared with six paraplegics. There has been a steady increase in the number of gymnastic injuries occurring over the years, which is similar, though less pronounced, than the increase in rugby injuries and no doubt reflects the increased popularity of the pastime. Despite the fact there were more women doing gymnastics, they have fewer accidents, possibly because they are less aggressive and do different forms of exercise such as natural exercises on the floor to music.

Few of these accidents occurred at school, most occurring in clubs. At school, few dangerous exercises-for example, somersaults ${ }^{12}$-are taught, and the coach at school is predominantly
TABLE I-Level and nature of transection of the cord ${ }^{\star}$

\begin{tabular}{|c|c|c|c|c|c|}
\hline \multirow[b]{2}{*}{ Level } & \multicolumn{2}{|c|}{ Neurology } & \multirow[b]{2}{*}{ Level } & \multicolumn{2}{|c|}{ Neurology } \\
\hline & Complete & Incomplete & & Complete & Incomplete \\
\hline $\mathrm{C} 1$ & - & - & C6 & 8 & 2 \\
\hline $\mathrm{C} 2$ & - & 1 & C6-7 & 1 & 1 \\
\hline C3 & - & - & C7 & 4 & 1 \\
\hline C3-4 & 1 & - & C7-8 & - & - \\
\hline C4 & 1 & - & C8 & 3 & - \\
\hline C4-5 & - & - & T10 & 2 & - \\
\hline C5 & 3 & 2 & $\mathrm{~T} 12$ & 1 & - \\
\hline C5-6 & - & - & & & \\
\hline
\end{tabular}

^In two patients there was no deficit and for five the information was incomplete.

TABLE II-Equipment used ${ }^{\star}$

\begin{tabular}{|c|c|c|c|}
\hline Case No & Equipment used & Mats & Catchers \\
\hline 9 & Trampette & Inadequate & No \\
\hline 10 & Trampette & Yes & No \\
\hline 11 & Springboard & Inadequate & Yes \\
\hline 12 & Trampette & & No \\
\hline 13 & Springboard & No & No \\
\hline 14 & Trampette & No & Yes \\
\hline 15 & Trampette & No & No \\
\hline 16 & Trampette & Yes & No \\
\hline 17 & Trampette & No & Yes \\
\hline 18 & Trampette & Yes & Yes \\
\hline 19 & Trampette & & No \\
\hline 20 & Springboard & No & No \\
\hline 21 & Trampette & Yes & Yes \\
\hline 22 & Trampette & No & Yes \\
\hline 23 & Trampette & Yes & No \\
\hline 24 & Trampette & No & No (vault) \\
\hline 25 & Trampette & No & \\
\hline 26 & Trampette & Yes & No \\
\hline
\end{tabular}

ॠThree patients were injured during leisure activities and were therefore not using equipment or catchers.

concerned with his pupils' overall education, welfare, and safety and knows them well.

Even within the school system there is a notable discrepancy between the aim of the state system, "which is not to breed top levelo sports men and women but to interest all school children in physicalo exercise in a way that improves their health and enjoyment for the rest of their lives." ${ }^{2}$ In the private system the exercises taught are ato를 the discretion of each gymnastics master, and very high competitive skills can be achieved. On the other hand, in the clubs the predominant interest is competitive achievement, the gymnasts come, of necessity, at the end of the day, and the coaches are not necessarily familiar with them or their standard.

Thirteen of the patients we saw were in the forces and three in theo police at one particular college. This high proportion demands an explanation. The army uses gymnastics for displays and to breed independence and qualities desirable in soldiers, such as aggression and courage-features not necessarily conducive to the learning of a윽 difficult skill. Moreover, a distressing number of the patients were under compulsion and pressure to do these exercises and not carrying them out voluntarily. One was in prison.

Most of those injured were club, county, or national standard $(R$ Walker, personal communication). This indicates that skill or high standard does not protect, the vital factor being the force generated by the more skilled performers who add to their momentum by using equipment. The greater skill of the international gymnastso does not compensate for the extra risks they take, particularly as $\Phi$ they are beginners to many of the newly invented, highly complex ${ }^{\text {? }}$ exercises that they attempt.

Previous studies have emphasised the high proportion of accidents caused by the somersault. This is because the head is $\stackrel{?}{?}$ carried forward and when struck transmits its force to the vulnerable cervical spine, a point that is substantiated by the frequency with which such injuries occur during rugby and 8 trampolining. The somersault is particularly difficult to teach응 because it is an all or nothing phenomenon. Great height and speed have to be achieved, usually by means of a trampette or spring- 


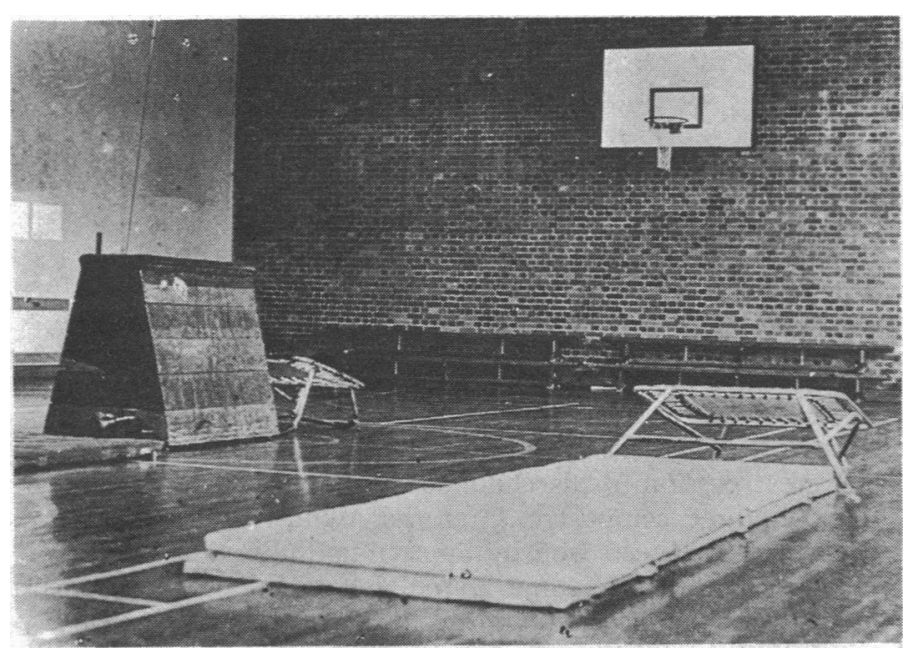

Scene of an actual accident. Note the old fashioned trampette and the lack of crash mats either side of the landing area.

board. This height and speed is very difficult to control, and rotation may lead to disorientation and hence a blow to the head.

Mats should be used to prevent injury, but this is only a secondary measure after the accident has occurred and is analogous to the use of a hard hat when horseriding. If you land on your head from more than three feet injury cannot be prevented however adequate the matting, just as there is no safe way of landing on one's head on a trampoline. Many of the accidents in our study were caused by vaults over boxes, where a similar increase in momentum was achieved.

The trampette is a little understood, much abused piece of equipment (figure). It is a muscle replacement, its angle aids rotation, it preserves energy, and it allows people, especially children, to achieve height and carry out exercises of spatial orientation. It enables people to do exercises, such as somersaults, that they do not have the muscles to achieve spontaneously. The gymnast can, however, over-rotate or leave the trampette at angles which will lead to missing the mat altogether, and catchers seem ineffective - that is, attempting to catch a $70-76 \mathrm{~kg}$ man coming off a trampette at speed is difficult, to say the least. The trampette's greatest danger is that it enables the gymnast to gain uncontrolled height, which can be corrected by neither gymnast nor catcher. The trampette is not used in Olympic disciplines, and the British Amateur Gymnastic Association acknowledges its danger and accordingly does not use it. The springboard serves the same purpose but is much safer.

The somersault has dominated our findings, but the other major cause of accidents was falls. These falls nevertheless caused injuries predominantly to the cervical spine. The falls resulted largely from static exercises and falls from ladders, ropes, and wall bars. The other type of fall resulted from falls from parallel bars or rings when the hands, as opposed to the feet, slipped.

The causes of these accidents are the most important aspect of this study, because if they can be identified then appropriate preventive steps could be taken. The accidents can be divided into those caused by the performer, those caused by the equipment, and those caused by the supervision. A few injuries were clearly due to the performer indulging in gymnastic type exercises independently-for example, outside a pub. In view of the large number of children and adults whom one sees doing somersaults on the beach or around pools such accidents must be remarkably rare. The extra force provided by gymnastic equipment is required to break the neck. We found few cases of injuries incurred in a gymnasium where the athlete was solely responsible for the accident. Some were unfit from lack of practice or because they were recovering from flu or suffering from toothache, but in almost all cases the accidents were caused by inadequate supervision.

Supervision is of two types. General supervision entails ensuring that dangerous equipment such as springboards and boxes is kept locked up and that the gymnasts are not allowed to use the equipment on their own. Many of our cases occurred as a result of unsupervised use of the gymnasium.

When a supervisor is in the gymnasium he must also ensure that dangerous exercises that require his immediate presence are not taking place simultaneously. Exercises such as a somersault from a springboard require the coach's personal supervision. Young people do not have the knowledge or insight to carry out somersaults unsupervised. When the coach was present, however, there were many faults, the worst example of which was a coach compelling a gymnast to do an exercise against his wishes. In other instances, although present in the gymnasium, coaches were not beside the trampette on which the students were allowed to undertake advanced manoeuvres, or the coaches were incapable of doing the exercises themselves.

The students were less to blame. In cases where they contributed to accidents they had been left unsupervised and tried too ambitious a programme. Gymnasts of all standards were injured, showing that greater skill does not afford protection, as, no matter how high the standard, when the advanced gymnast tries a new exercise he is a beginner. The beginner trusts his coach and thus believes what the coach says is correct and safe. The athlete can be motivated by the coach to attempt exercises beyond his abilities, particularly if he is young. The gymnast may be tired or under stress, which may be prompted by the coach who is training gymnasts for a competition.

It is difficult in the United Kingdom to generalise and institute correct practices, as the accidents occur in difficult circumstances where different authorities are responsible. With regard to accidents that take place during leisure activities or social activities clearly efforts must be made to increase awareness of the dangers-for example, of performing somersaults in the road.

In view of the serious accidents that can occur and the discrepancy of responsibility clear rules are required. The British Amateur Gymnastic Association is clearly responsible only for the conduct within clubs and can give only general guidelines to the schools. Its record within the clubs is excellent and, taking into account the increase in the number of gymnasts, clubs, and gymnasiums, there may have been a relative fall in the number of accidents, although the absolute number has increased. This is due to better coaching programmes, improvement in the facilities and the understanding of the physiological mechanisms of exercise, and a better and more structured training programme. Hopefully, the standards set up by the British Amateur Gymnastic Association can be applied universally, and these distressing accidents with their attendant morbidity and mortality can be further reduced so that the sport can thrive, developing the gymnasts' bodies instead of crippling them.

I thank my colleagues for the case histories; Mr Nuseibeh, Dr Frankel, and $\mathrm{Mr}$ McSweeney for allowing me to study their cases; Mr Atkinson, technical adviser to the British Amateur Gymnastic Association; Mr Rob Walker, technical officer of the British Trampoline Federation, M Bean, physical education adviser, Buckinghamshire; and $M$ Brigden and $A$ Adamson, Beacon School, for their technical advice on gymnastics.

\section{References}

1 Sparks JP. Half a million hours of rugby football -the injuries. Br f Sports Med 1981;15:30-2. 2 Young JS, Burns PE, Bowen AM, McCrutchen R. Spinal cord injury statistics. Phoenix, Arizona: Good Samaritan Medical Center, 198

3 Frankel HL, Hancock DO, Hyslop G, et al. The value of postural reduction in the initial management of closed injuries of the spine with paraplegia and tetraplegia. Paraplegia 1969;7:179.

4 Shields CL, Fox JM, Stauffer ES. Cervical cord injuries in sports. The Physician and Sports Medicine 1978;6:71-6.

5 Steinbruck K, Paeslack V. Analysis of 139 spinal cord injuries due to accidents in water sports. Paraplegia 1980;18:86-93.

6 Bauze RJ, Adrian GM. Experimental production of forward dislocation in the human cervical spine. F Bone foint Surg 1978;60(B):239-45.

Silver JR. Injuries of the spine sustained in rugby. Br Med $\mathcal{F}$ 1984;288:37-43.

8 Silver JR, Silver DD, Godfrey JJ. Trampolining injuries of the spine. Injury 1986;17:117-24.

9 Vinger PF, Hoerner EF, eds. Sports injuries: the unthwarted epidemic. Littleton, Massachusetts: PSG Publishing Company, 1981:27-8.

10 Lowry CB, Leveau BF. A retrospective study of gymnastics injuries to competitors and noncompetitors in private clubs. Am $\mathcal{F}$ Sports Med 1982;10:237-9.

11 Garrick JG, Requa RK. Epidemiology of women's gymnastic injuries. Am $f$ Sports Med 1980;8:261-4

12 Cane J. Children losers in battle of playing fields. Daily Telegraph 1985 Dec 27:13 (cols 7 and 8).

(Accepted 5 August 1986) 